\title{
Morphological Diversity of Peroneus Tertius: A Cadaveric Study
}

\author{
Kosgallana EW ${ }^{1}$, Eshwara $\mathrm{JM}^{1}$, Dissanayake $\mathrm{J}^{1}$ \\ ${ }^{1}$ Department of Anatomy, Faculty of Medicine, University of Peradeniya
}

\begin{abstract}
Objective

The objective of this study was to demonstrate morphological anatomical variations of the peroneus tertius muscle which may have important clinical and surgical implications.
\end{abstract}

\section{Materials and methods}

Fifty four specimens of anterior compartment of the leg which were dissected routinely according to the undergraduate course were examined for variations of the above muscles and the anatomy was further defined using appropriate dissection methods.

\section{Results}

A wide variation was found with regard to the morphology of peroneus tertius and the extensor digitorum longus muscles with considerable differences between the legs of the same cadaver.

When considering important variations deviating considerably from the normal structure, a variation of the distal attachment of peroneus tertius muscle in two specimens revealed that in addition to the normal attachment to the shaft of the fifth metatarsal, an additional slip inserted to the extensor expansion of the fifth toe. It apparently replaced the fourth tendon of extensor digitorum longus, which only had three divisions in these specimens.

Seventeen of the specimens had a single muscle belly giving rise to 5 tendons which had the usual distal attachments of the peroneus tertius and the extensor digitorum longus muscle as stated below. Absence of peroneus tertius was noted in one specimen.

\section{Conclusion}

The anatomical structure of the peroneus tertius vary substantially from individual to individual, inclusive of differences existing between the left and the right lower limbs of the same cadaver.

Key words: peroneus tertius, extensor digitorum longus, anatomical variations, Jones fracture.

\section{Introduction}

Peroneus tertius or fibularis tertius and extensor digitorum longus are muscles in the anterior compartment of the leg. Although the peroneus tertius was once thought to be a muscle unique to humans (1) it has also been found in certain anthropoid apes $(2,3)$. 
The earliest recorded description of these muscles is by Vesalius (6). Some contemporaries of Vesalius rejected peroneus tertius as a separate muscle and described it as a part of extensor digitorum longus.

Proximal insertion of the muscle is on the distal third or more of the fibula as well as on the interosseus membrane and anterior intermuscular septum $(5,6,7)$. The distal attachment is classically described as to the base of fifth metatarsal bone $(6,7)$. Evidence of variations of this insertion are described to be to shaft of the fifth metatarsal, fascia covering fourth interosseous space and base of fourth metatarsal $(6,7,8,9)$. Though the tendon of peroneus tertius is described as usually one, work of Ericikt et al (8) has found that there can be 2 tendons with a slip.

Although interconnections between extensor digitorum longus muscle and peroneus tertius is mentioned in textbooks the precise manner of connection is not well documented. Stevens et al (9) however has documented intertendinous connections between peroneus tertius and extensor digitorum longus tendon.

Considering the action of this muscle, work of (15) has found that the muscle is important in the swing phase of the gait to level the foot and help toes clear the ground along with extensor digitorum longus and tibialis anterior. This muscle is implicated in the occurrence and management of Jones fracture (17). The muscle is additionally used in filling soft tissue defects in the limbs (16).

The extensor digitorum longus muscle arises from the inferior surface of the lateral condyle of tibia, proximal three quarters or upper half of the medial surface of fibula, adjacent anterior surface of interosseous membrane, deep fascia, anterior crural intermuscular septum and the fascial septum between itself and tibialis anterior. It descends to form a tendon which divides in to four on the dorsum of the foot each joined by a slip from the extensor digitorum brevis to form dorsal digital expansions through which they finally insert to the bases of distal and middle phalanges of lateral four toes. $(6,7)$ The action of this muscle is to dorsiflex the foot and extend the toes.

\section{Method}

Fifty four specimens received by the Department of Anatomy, Faculty of Medicine, University of Peradeniya for studying purpose of students were used for this study. Initially medical students dissected the specimens under the guidance of the academic staff members. Following completion of the relevant dissections, the lower limbs were thoroughly observed for variations of peroneus tertius muscle and its tendons and subsequent dissections carried out to clearly define the anatomy.

\section{Results}

Results showed a wide variation of morphology with remarkable differences noted between the legs of the same cadaver. Here are described five variations that significantly deviated from the normal text book description. 
In the right leg of a female cadaver (figure 2) the peroneus tertius muscle gave rise to two tendons. The lateral tendon inserted into the base of the fifth metatarsal. The medial slip continued to the fifth toe beyond the fifth metatarsal, apparently replacing the fourth tendon of extensor digitorum longus. Extensor digitorum longus muscle gave rise to three tendons rather than the usual four, each heading towards second, third and fourth toes. In the left leg of the same cadaver both extensor digitorum longus and peroneus tertius originated as a single muscle with 2 muscle bellies splitting high in the leg. Extensor digitorum longus showed no variation on insertion. Peroneus tertius split in to 2 slips with the lateral slip attaching to fifth metatarsal head and medial slip joining the fascia over fourth interosseus space (figure 3).

A similar variation to figure 2 was noted in another female cadaver on the left leg with two tendons arising from peroneus tertius and 3 tendons arising from extensor digitorum longus. Additionally there was a prominent intertendinous slip extending from the tendon of peroneus tertius attached to the fifth toe to the tendon of extensor digitorum longus attached to the fourth toe (figure 4).

In two male specimens on the left leg the two muscles had extensive intermuscular connections proximally apparently forming a single muscle which separated in to two muscle bellies distally. In both specimens the medial muscle belly representing the extensor digitorum longus gave rise to 3 tendons and the lateral muscle belly representing the peroneus tertius gave rise to 2 tendons as above (figure 5).

Seventeen of the specimens showed a single muscle belly arising from the anterior surface of the tibia giving rise to five tendons which had distal attachments to the usual distal attachments of the peroneus tertius and the extensor digitorum longus (figure 6).

Absence of Peroneus tertius was noted in one specimen, which was the left leg of a male cadaver (figure 7).

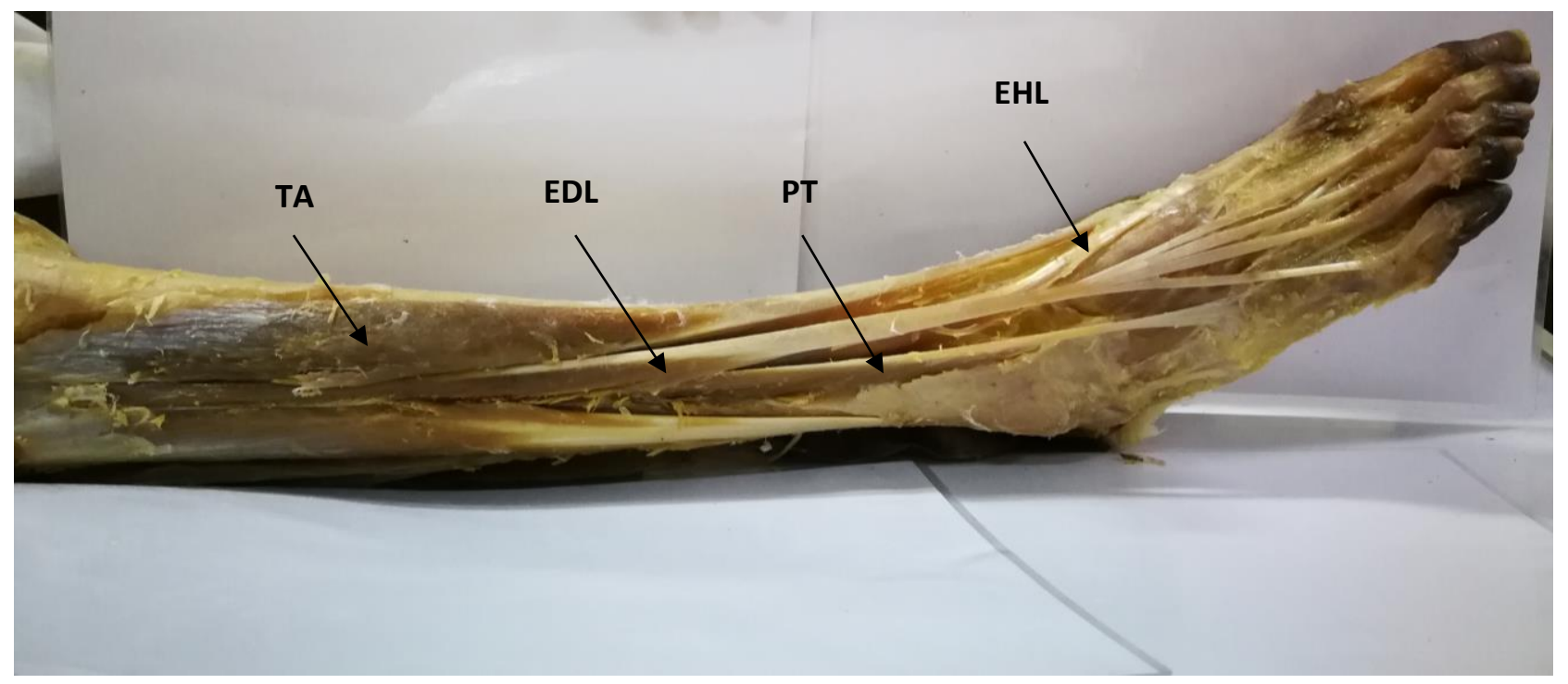

Figure 1. Normal morphology of peroneus tertius and extensor digitorum longus. 


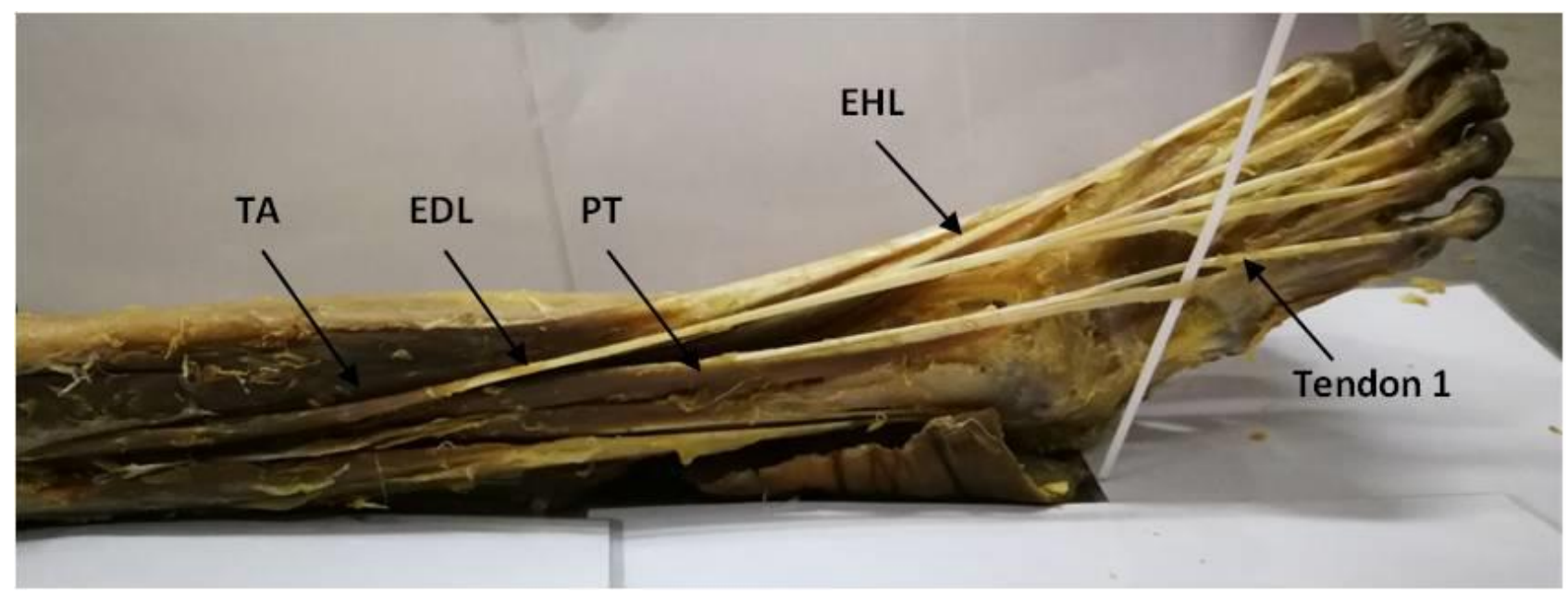

Figure 2. Fourth tendon of extensor digitorum longus replaced by a tendon of peroneus tertius (Tendon 1)

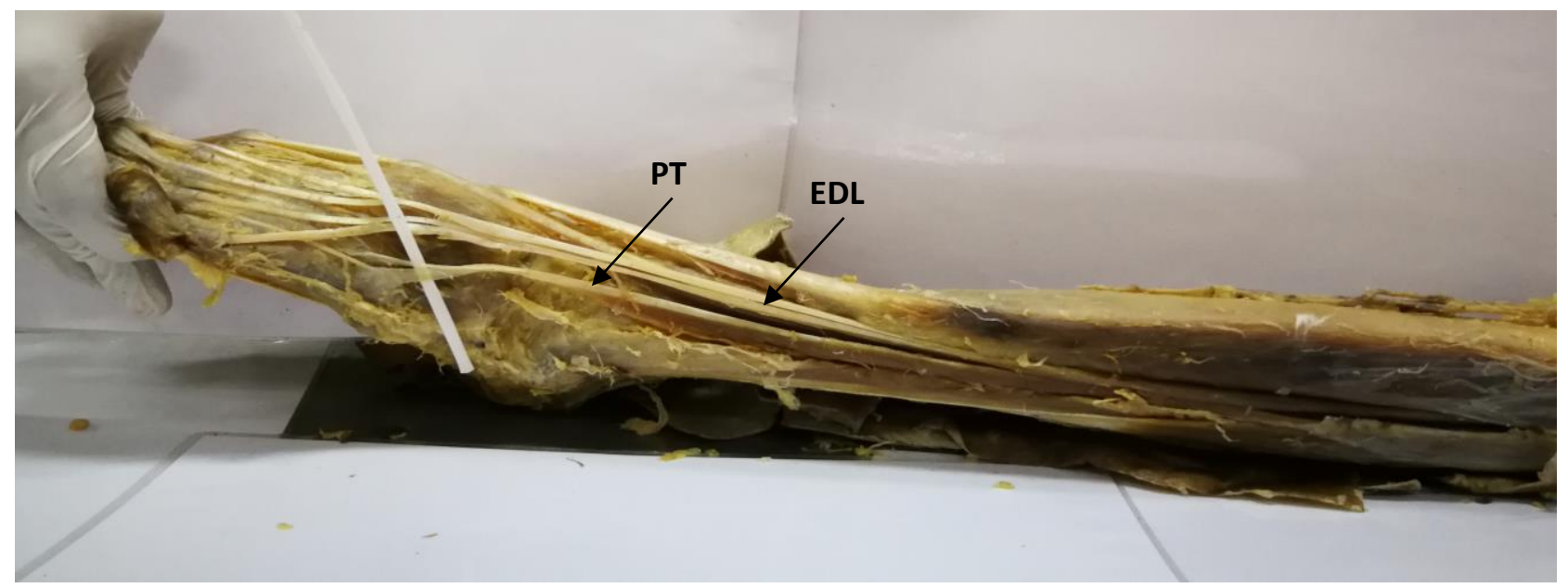

Figure 3. Peroneus tertius split in to 2 slips with the lateral slip attaching to fifth metatarsal head and medial slip joining the fascia over fourth interosseus space.

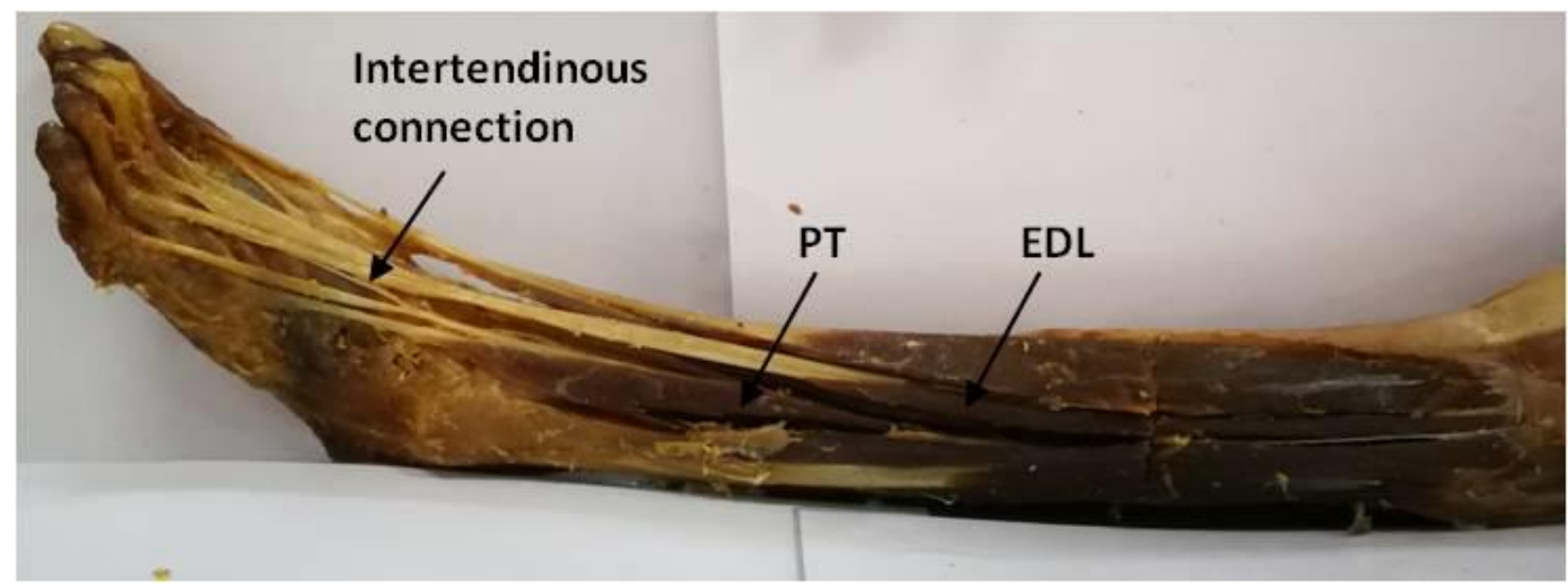

Figure 4. Fourth tendon of extensor digitorum longus replaced by a tendon of peroneus tertius with the addition of an intertendinous slip between tendons of peroneus tertius and extensor digitorum. 


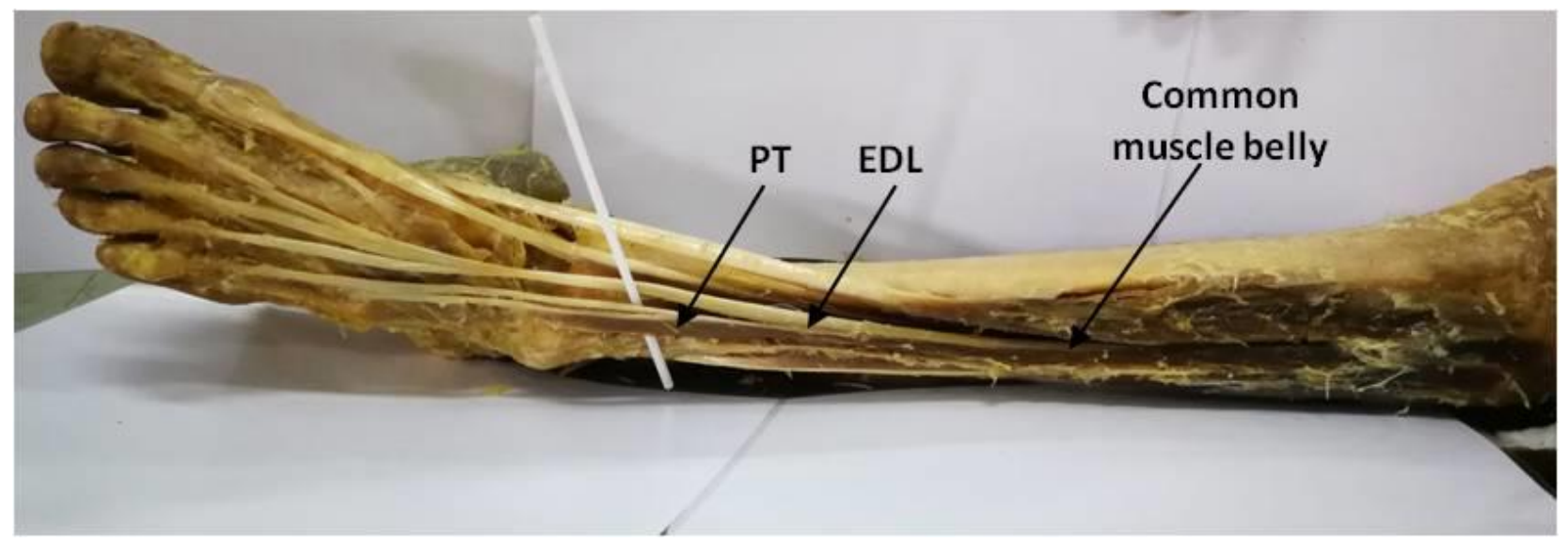

Figure 5. Proximally single muscle giving rise to two muscles representing peroneus tertius and extensor digitorum longus giving rise to two tendons and three tendons respectively.

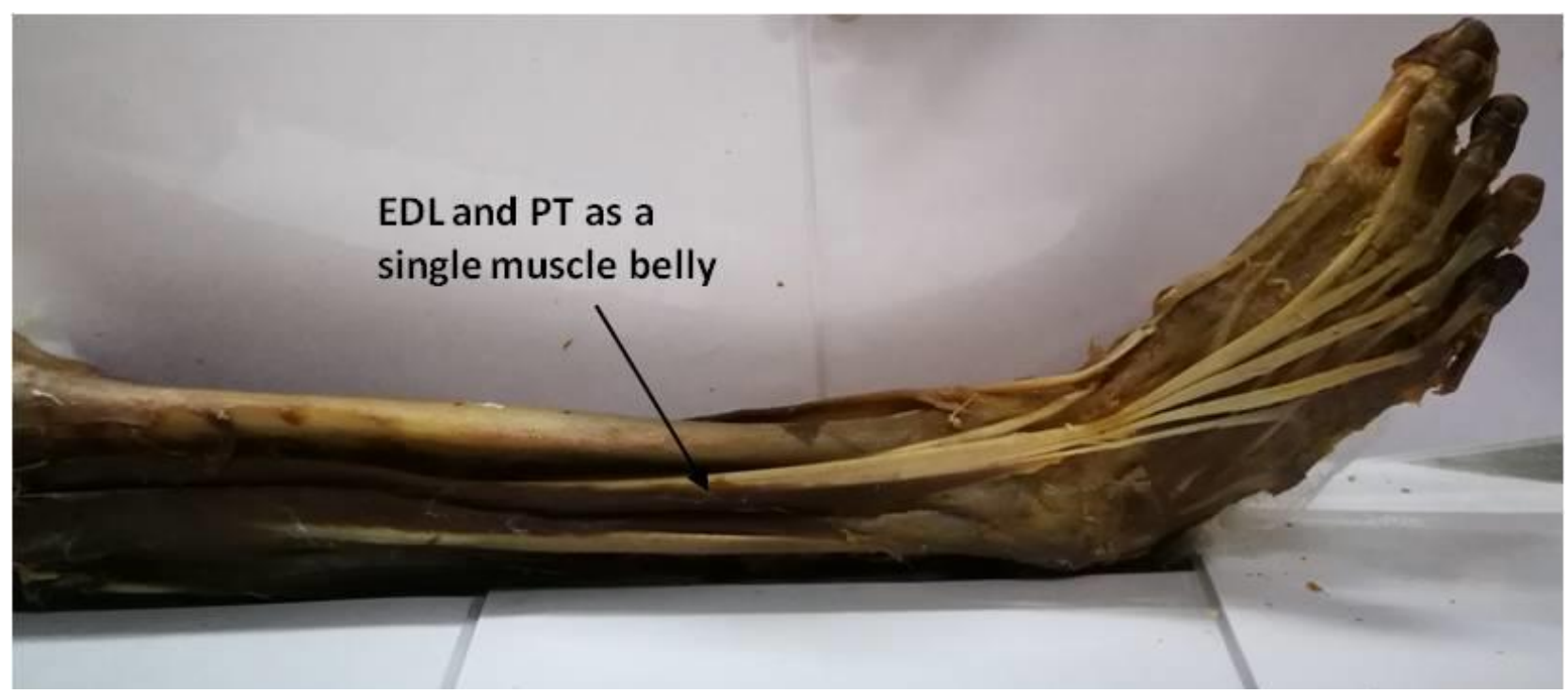

Figure 6. A single muscle replacing the peroneus tertius and extensor digitorum longus giving rise to five tendons.

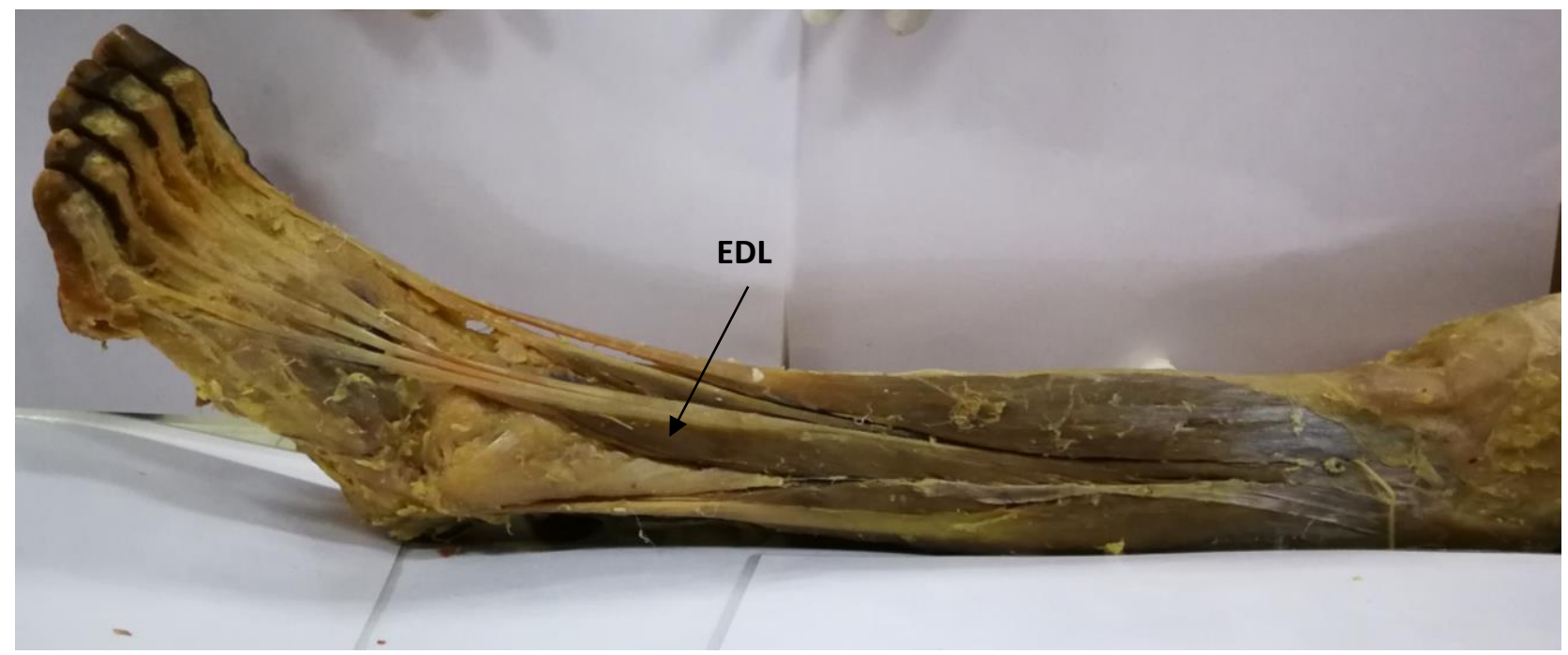

Figure 7. Absent Peroneus Tertius. 


\section{Discussion}

A few variations involving peroneus tertius muscle and extensor digitorum longus muscle have been reported earlier. Absence of peroneus tertius tendon has been reported by many (5), (9), (13), (14), (18) with the percentage ranging from 1.5 upto $10.45 \%$ of the studied samples. Absence of peroneus tertius was noted in one of the fifty four $(1.85 \%)$ of the specimens used in our study. Yildiz and Yalcin, 2012 (11) reported on a peroneus tertius muscle arising from extensor hallucis longus muscle. Rao et al., 2014 (21) as well as Bhatt, Modi and Mehta, 2010 (22) have reported of cases where extensor digitorum longus tendon has divided into 3 slips which inserted into $2^{\text {nd }}, 3^{\text {rd }}$ and $4^{\text {th }}$ toes and a slip from Peroneus tertius tendon supplying the $5^{\text {th }}$ toe which is one of the variations we have found in our study. The anatomy of peroneus tertius and extensor digitorum longus tendons are important in surgical reconstructions relevant to trauma to the dorsal aspect of foot. Additionally peroneus tertius is used as a free flap to treat soft tissue defects and osteomyelitis of lower limbs (10), (19). Gaulrapp and Heimkes, 1997 (20) mentions a case where peroneus tertius tendon was used to repair ruptured tibialis anterior tendon. The variation of figure 2 and 3 might hinder the use of peroneus tertius tendon for above mentioned purposes as extension of $5^{\text {th }}$ toe might be affected with the removal of peroneus tertius muscle/tendon.

Proneus tertius is an important anatomical boundary used in the placement of arthroscopy portals (23). Individual variability of this muscle may necessitate use of imaging techniques prior to such procedures. In the cases with increased muscle bulk as well as the replacement of the fourth tendon of the extensor digitorum longus by a slip from peroneus tertius may depict a more important role of peroneus tertius in its function. The implication of such a variation in the occurrence and treatment of Jone's fracture is also unsure.

The evolutionary origin of the peroneus tertius has been of controversies since its first description in the $16^{\text {th }}$ century. It was considered a part of extensor digitorum longus by some anatomists (5). Joshi, Joshi and Athavale, 2006 mentions that extensor digitorum brevis of the foot has migrated upwards to give rise to the peroneus tertius (13). In our study as seventeen out of the fifty four specimens had a common muscle belly representing both muscles, origin of peroneus tertius by extensor digitorum longus may be more suggestive.

\section{Acknowledgement}

None

\section{Conflict of interest}

None

\section{Corresponding Author}

E. W. Kosgallana

C-39, Upperhantana Quarters, University of Peradeniya, Peradeniya.

Tel: 0775719942

E-mail: warukos@gmail.com 


\section{BY 4.0}

This is an Open Access article distributed under the terms of the Creative Commons Attribution 4.0 license (unless stated otherwise) which permits unrestricted use, distribution and reproduction in any medium, provided the original work is properly cited. Copyright is retained by the author(s).

\section{References}

1. Hepburn, D. (2019). Comparative Anatomy of the Muscles and Nerves of the Superior and Inferior Extremities of the Anthropoid Apes Part II. Journal of Anatomy, pt 3(26), pp.334-335.

2. Morton, D. (1924). The peroneus tertius muscle in gorillas. The Anatomical Record, 27(5), pp.323-328.

3. Straus, J. and William, L. (2019). The Foot Musculature of the Highland Gorilla (Gorilla beringei). The Quarterly Review of Biology, [online] 5(3), p.275. Available at: http://www.jstor.org/stable/2808293 [Accessed 3 May 2019].

4. A. Vesalius, "De corporis humani fabrica libri septem," Liber II, Basileae, 1543

5. Krammer, E., Lischka, M. and Gruber, H. (1979). Gross anatomy and evolutionary significance of the human peroneus III. Anatomy and Embryology, 155(3), pp.291-302.

6. Anatomy text books

Drake, R., Vogl, A. and Mitchell, A.
(2011). Gray's Anatomy for Student's. $2^{\text {nd }}$ ed. Churchill Livingstone, p.840.

7. Sinnatamby, C. (2011). Last's Anatomy Regional and Applied. $12^{\text {th }}$ ed. Churchill Liivingstone, p.144.

8. Ercikti, N., Apaydin, N., Kocabiyik, N. and Yazar, F. (2016). Insertional Characteristics of the Peroneus Tertius Tendon: Revisiting the Anatomy of an Underestimated Muscle. The Journal of Foot and Ankle Surgery, 55(4), pp.709-713.

9. Stevens, K., Platt, A. and Ellis, H. (1993). A cadaveric study of the peroneus tertius muscle. Clinical Anatomy, 6(2), pp.106110.

10. Sirasanagandla, S. (2014). A Rare Case of Variant Morphology of Peroneus Tertius Muscle. JOURNAL OF CLINICAL AND DIAGNOSTIC RESEARCH.

11. Yildiz, S. and Yalcin, B. (2012). An unique variation of the peroneus tertius muscle. Surgical and Radiologic Anatomy, 34(7), pp.661-663.

12. Vieira, A., Monteiro, A., Nacur, F., Coutinho, R., Direito, T. and Torres, D. (2018). Prevalence and Topography of the Peroneus tertius Muscle: a Study of Human Cadavers. Journal of Morphological Sciences, 35(02), pp.106-109.

13. Joshi, S., Joshi, S. and Athavale, S. (2006). Morphology of peroneus tertius muscle. Clinical Anatomy, 19(7), pp.611614. 
14. Das, S., Suhaimi, F., Latiff, A., Hlaing, K., Ghafar, N. and Othman, F. (2009). Absence of the peroneus tertius muscle: cadaveric study with clinical considerations. Romanian Journal of Morphology and Embryology, 50(2), pp.509-511.

15. Jungers, W., Meldrum, D. and Stern, J. (1993). The functional and evolutionary significance of the human peroneus tertius muscle. Journal of Human Evolution, 25(5), pp.377-386.

16. Gusmão, L., Lima, J., Duarte, F., Souto, A. and Couto, B. (2013). Bases anatômicas para utilização do músculo fibular terceiro em retalhos miocutâneos. Revista Brasileira de Cirurgia Plástica, 28(2), pp.191-195.

17. Vertullo, C., Glisson, R. and Nunley, J. (2004). Torsional Strains in the Proximal Fifth Metatarsal: Implications for Jones and Stress Fracture Management. Foot \& Ankle International, 25(9), pp.650-656.

18. Witvrouw, E., Vanden Borre, K., Willems, T., Huysmans, J., Broos, E. and De Clercq, D. (2006). The Significance of Peroneus Tertius Muscle in Ankle Injuries. The American Journal of Sports Medicine, 34(7), pp.1159-1163.
19. Arnold, P., Yugueros, P. and Hanssen, A. (1999). Muscle flaps in osteomyelitis of the lower extremity: a 20-year account. Plastic and Reconstructive Surgery, 104(1), pp.107-10.

20. Gaulrapp, H. and Heimkes, B. (1997). Peroneus tertius tendon repair following rupture of the anterior tibial tendon (a case study). Der Unfallchirurg, 100(12), pp.979983.

21. P, A., Rao, M., Rao, A., Nayak, S. and Shetty, S. (2014). Anomalous Pattern of Tendinous Slips of Peroneus Tertius and Extensor Digitorum Longus Muscles in the Foot- A Clinically Important Variation. Gulhane Medical Journal, 56(3), p.179.

22. Bhatt, C., Modi, M. and Mehta, C. (2010). Variation In Peroneus Teritius Tendon And Its Clinical Implication. Journal of Orthopaedics, [online] 2(7), p.e1. Available at: http://www.jortho.org/2010/7/2/e1 [Accessed 2 May 2019].

23. Amendola, A. and Stone, J. (2010). The foot and ankle. $1^{\text {st }}$ ed. Philadelphia: Saunders/Elsevier, pp.26-29. 